\title{
GEOGRAFIA NARRADA NO/DO/COM O COTIDIANO ESCOLAR: UM ESTUDO A PARTIR DO CONCEITO DE TERRITÓRIO
}

\author{
Carlos Martins* \\ Marcos Reigota**
}

Resumo: Este artigo apresenta um estudo a partir do conceito de território e tem como objetivo buscar no/do/com o cotidiano de duas instituições públicas estaduais localizadas no município de Itapetininga/SP os microterritórios que ocupam os seus espaços, bem como a correlação desses microterritórios com aqueles de uma região metropolitana.

Palavras-chave: Cotidiano escolar. Território. Desconstrução. Narrativas

\section{GEOGRAPHY NARRATED IN / EVERYDAY SCHOOL: A STUDYFROM THE CONCEPT OF TERRITORY}

Abstract: This article presents a study from on the concept of territory aims to get in /from the everyday life of two state public schools in the municipality of Itapetininga / SPmicroterritorial occupying their spaces, and the correlation of these microterritorial with those of a metropolitan area

Key Words: Daily school routine. Territory. Deconstruction. Narratives

\section{Introdução}

Território. Conceito enraizado, principalmente, no relevo do paradigma da ciência geográfica. Difícil manipulação. Correremos o risco necessário de embrenharmos no espaço-tempo e buscarmos abordagens e concepções sobre o conceito. Não queremos, porém, apagar as contribuições sobre esse conceito realizadas até o momento e nem descaracterizá-las, muito menos desconsiderar o modo como ele é normalmente empregado pela ciência geográfica; buscamos, sim, a desconstrução ${ }^{1}$ do conceito de território para que se possa alcançar o micro numa escala espacial. O micro que possibilita

\footnotetext{
${ }^{1}$ Revirar o instituído por normas e regras
}

uma análise do espaço-tempo sem que para isso seja necessário ligar o território tão e somente ao solo, mas também às relações humanas e não humanas que produzem e carregam territórios consigo. Para isso, é inevitável que o conceito seja desagregado, mas não desligado do macro.

Enraizado no relevo do paradigma, esse conceito, como é normalmente utilizado pela ciência geográfica, é impedido de avançar sobre as entranhas que se fazem por entre os muros da escola ou de qualquer outro espaço que não esteja relacionado ao macro. Dessa forma, buscamos ultrapassar, cavar brechas na barreira paradigmática, que

* Professor efetivo de Geografia do Estado de São Paulo. Mestre em Educação ( 2011) pela Universidade de sorocaba - Uniso. Email: caromimar@yahoo.com.br

** Doutor pela Universidade Católica de Louvain. Pós-doutorado na Universidade de Genebra. Bolsista de Produtividade Científica do Cnpq (nível 2). Docente do PPG em Educacão da Universidade de Sorocaba - Uniso. Email: marcos.reigota@prof.uniso.br 
entrava o conceito de território e o desqualifica, considerando-o como sendo, também, formado pelas relações promovidas pela subjetividade.

Buscamos estímulos a fim de nos desvencilharmos de vez da representação do território como uma 'coisa' -, como um "território-coisa'", segundo Souza (2009, p. 67). No entanto,

"descoisificar" o território não quer dizer negligenciar a materialidade do espaço. Significa, isso sim, refinar o conceito e conferir-lhe maior rigor, assim enriquecendo o arsenal conceitual à disposição da pesquisa sócio-espacial. Parafraseando e adaptando uma formulação célebre, não há aqui nada a perder, a não ser grilhões ideológicos e teóricos. (SOUZA, 2009, p.67-68, grifo meu)

Para Souza (2006, pg. 81),

a bem da verdade, o território pode ser entendido também à escala nacional e em associação com o Estado como grande gestor (se bem que, na era da globalização, um gestor cada vez menos privilegiado). No entanto, ele não precisa e nem deve ser reduzido a essa escala ou à associação com a figura do Estado. Territórios existem e são construídos (e desconstruídos) nas mais diversas escalas, da mais acanhada (p. ex., uma rua) à internacional.

Ao considerar a construção e desconstrução dos territórios a partir de diversas escalas temporais, Souza (2006, p. 81) acrescenta:

séculos, décadas, anos, meses ou dias; territórios podem ter um caráter permanente, mas também podem ter uma existência periódica, cíclica. Não obstante essa riqueza de situações, não apenas 0 senso comum, mas também a maior parte da literatura

científica, tradicionalmente restringiu o conceito de território à sua forma mais grandiloquente e carregada de carga ideológica: o "território nacional".

Assim, o autor apresenta criticamente a concepção de macro território, levando-nos a pensar - desde as limitações aí implicadas - num espaço estruturado e "organizado" por um poder central detentor de uma grande porção de terra. E registra o poder como forma de subdividir o território em outras porções menores de terra para impor sua vontade (do Estado). Ao esclarecer que o território não deve ser pensado somente como uma figura pertencente ao poder do Estado, nem associado exclusivamente ao macro, Souza (2006) considera que o território pode ser concebido, também, a partir das mais variadas escalas espaciais; segundo ele, "da mais acanhada à internacional" (SOUZA, 2006, p. 81). Ou seja, podemos concebê-lo e analisá-lo desde uma classificação micro, ou, até mesmo, segundo esse autor, nano. Teríamos então os nanoterritórios

[...] em que as "fronteiras" englobam uma rua ou um trecho de rua, um prédio ocupado por sem-teto, uma prisão, parcelas das arquibancadas de um estádio de futebol..., nos leva a experimentar, em matéria de "campos de força" do poder espacializado - em outras palavras, em matéria de territórios -, realidades espaço-temporais bem diferentes da aparente fixidez das fronteiras estatais. É a escala, por excelência, dos oprimidos e de suas táticas, com suas resistências quotidianas inscritas no espaço ou expressas espacialmente, como já assinalara Certeau (1996). É a escala mais abrangente dos "micropoderes" [...] (SOUZA, 2009, p. 67). 
Gostaríamos de substituir, em parte, a noção de nanoterritório utilizada por Souza para o que chamamos de 'microterritório'. Este delimitado por fronteiras visíveis e não visíveis, palpáveis e não palpáveis. Resultado da desconstrução do conceito de território, normalmente, entendido pela Geografia. Mistura entre o território estudado por alguns autores ligados à Geografia e o exposto pelo filósofo Gilles Deleuze por meio da obra $O$ abecedário de Gilles Deleuze ${ }^{2}$. Pode ser demarcado mesmo que temporariamente. É transitório. Pode ser feito e desfeito em minutos, segundos. Pode estar relacionado ao solo, mas não é preso a ele.

Segundo Deleuze (1988-1989, p. 4) "o território é o domínio do ter", e ainda para esse autor "o território são as propriedades do animal, e sair do território é se aventurar".

Dessa forma, procuramos por meio dos microterritórios abordar questões de afeto, em que afinidade e poder põem em jogo relações preconceituosas, de exclusão, adesão, negação, pertencimento, gênero enfim, relações humanas complexas que ocorrem no cotidiano escolar.

\section{Cotidiano escolar em narrativas: buscando territórios}

Buscamos, por agora, apresentar narrativas sobre o cotidiano escolar, muitas das quais surgidas após inúmeras

\footnotetext{
${ }^{2}$ Ver BOUTANG, Pierre-André; PARNET,Claire.. O Abecedário de Gilles Deleuze. Paris: Éditions Montparnasse/Brasil: TV Escola, Ministério da Educação.Tradução e Legendas: Raccord [com modificações], A transcrição integral do vídeo encontra-se disponível em: $<$ www.ufrgs.br/corpoarteclinica/obra/abc.prn.p df $>$
}

observações no/do/com o espaço escolar durante os anos de 2009, 2010 e meados de 2011. Essas observações aconteceram em diversos momentos enquanto professores no exercício de nossas funções e também através das nossas andanças como pesquisadores.

\section{Buscando}

Dois braços estendidos, delimitados por uma construção humana, concretizada para separar, definir papéis. Tijolo, ferro, cimento, concreto. Um grande espaço aberto que possibilita a travessia da visão. De um lado a temperatura é amenizada pelo exaustor, fixado na parede, entre o espaço aberto e o teto manchado pela gordura das frituras. Do outro lado o vento acaricia o ambiente. As mãos separadas pela delimitação física às vezes até se tocam de leve, um breve encontro. Os olhares que se cruzam são rápidos, situação efêmera. Movimentos velozes de braços que entregam e pegam. Merendeiras de um lado, alunos de outro. O prato, objeto frágil, basculante, de plástico, usado várias vezes ao dia. Judiado, às vezes jogado, desprezado sem clemência por aquele que há pouco matou sua fome. 0 prato. Alegria da maioria. Deve cumprir bem sua função; estar cheio. Objeto privilegiado que avassala, desbrava fronteiras, explora, conhece bem os dois territórios; a cozinha e o refeitório. Pode entrar e sair.

"A disciplina procede em primeiro lugar à distribuição dos indivíduos no espaço. Para isso, utiliza diversas técnicas." (FOUCAULT, 1987, p.121). 
Os avisos nas portas, nas paredes, às vezes pendurados em colunas do prédio. Avisos que indicam o horário de atendimento, a hora do expediente; folhas de fundo branco com letras em negrito, fonte 54. Avisos simples, mas visíveis informam, impõem limites; horários. De "tal hora a tal hora" o atendimento será permitido. O mesmo papel com letras grandes impõe restrições ao território como um todo. Se não é hora de atendimento o acesso também não deve ocorrer. E mesmo que fosse horário de expediente o acesso deve ser com cautela. Alguns obstáculos não devem ser ultrapassados. Os limites devem ser respeitados. Normas do sistema.

Secretaria, diretoria, sala dos professores. Limites bem estabelecidos, delimitados fisicamente. Nas portas anotações que indicam o proprietário e a propriedade. Indicam dominações; denominações de quem pode entrar e deixar sem pedir licença. De quem pode mexer, remexer nos utensílios.

Diretoria. Território repleto de mesas com papéis que decidem, restringem. Território temido por muitos alunos, pais de alunos, funcionários, professores.

Sala dos professores. Interessante território. Geralmente uma mesa que comporta objetos para serem vistoriados pelos habitantes. Quase sempre habitado. Protegido por paredes que impedem ou pelo menos tentam impedir o contato com aqueles que fazem uso dos pequenos bancos e carteiras das salas de aula. Outros que não fazem parte diretamente do cotidiano escolar devem ser cautelosos ao adentrar o território dos professores; o risco de não se adequar é grande.
Não é anormal que os estudantes no/do/com o cotidiano escolar apontem as cabeças de leve, com cuidado para pedir um favor a alguém na sala dos professores. Movimentos mínimos que quase nem se mostram são direcionados ao procurado no território. A cautela é motivo lógico de preocupação daquele que vem de outro território; estaria infringindo normas de conduta num território alheio. Todo cuidado não é muito.

"Adoro bater papo com os professores sobre a matéria e as coisas que eu faço no meu dia-a-dia. Mas na hora do intervalo os alunos não podem entrar na secretaria e nem na sala dos professores. Por um lado eu acho certo, pois os professores precisam de paz em alguns momentos." (Aluna do $3^{\circ}$ ano do Ensino Médio)

"Às vezes eu preciso pedir alguma coisa na sala dos professores, mas eu não vou; fico com medo sei lá do que." (Aluna da $8^{\circ}$ ano do Ensino Fundamental)

No entanto, quando se trata do pátio, das salas de aula, da quadra de esportes, dos sanitários, dos corredores fora dos limites administrativos ocorrem fenômenos contrários.

Nas salas de aula; limites físicos que correspondem aos seus respectivos proprietários pelo menos durante um ano letivo. Não importa; nesse período as letras e números logo acima das portas mostram quais sujeitos têm o direito de entrar. Professores e alunos agora podem compartilhar o mesmo território. No entanto deve-se obedecer aos horários e/ou os escritos que indicam "quem pode e quem não pode". A mesma sala é usada 
muitas vezes por turmas diferentes em horários diferentes.

Mesmo numa sala, escolhemos um território. Entro numa sala que não conheço, procuro o território, lugar onde me sentirei melhor. E há processos que devemos chamar de desterritorialização, o modo como saímos do território. (DELEUZE, 1988-1989, p. 20-21)

Professores, professoras, alunos e alunas dividem o mesmo território físico, delimitado por paredes, carteiras, mesas. O espaço da frente; do professor. Outro território que se forma no território. Uma mistura de fronteiras visíveis e não visíveis. Mas que são legitimadas pelo poder constituído na sala de aula. A lousa, objeto destinado ao professor. As carteiras enfileiradas pertencentes aos alunos. Territórios transitáveis por alunos e professores. Mas não pertencentes a qualquer um deles. Uma mistura de delimitações físicas, afetivas, de pertencimento, de poder...

Os banheiros dos alunos. Dos alunos. Não é proibida a entrada de outros, de professores, por exemplo, mas isso dificilmente ocorre. O próprio professor evita utilizar o sanitário destinado aos alunos. Disso, poderiam surgir pequenas revoltas, como não é novidade nos cotidianos escolares: "se eles podem porque nós alunos não podemos utilizar o sanitário dos professores?".

Alunos utilizando o sanitário dos professores. Quebra das normas. Sinal de que as regras estão sendo desrespeitadas. Caos.

Caos. O pátio. Território propício para o surgimento das táticas. Nele afloram sons que não são permitidos em ambientes restritos da escola. As normas ainda prevalecem. As regras também vivem, sobrevivem em meio às táticas. Território aberto aos professores e funcionários da escola, mas é do aluno. Delimitado e preparado para comportar os alunos.

Apesar de delimitado geograficamente pelos muros da escola, o pátio é captador de complexidades, ações, fatos, discussões, conversas, transgressões que só poderiam ocorrer na rua, longe das normas e regras do cotidiano escolar.

Até o momento, narramos apenas alguns territórios no/do/com o cotidiano escolar que são delimitados fisicamente por obras humanas palpáveis, concretas, que podem ser observadas, tocadas, ouvidas. São objetos facilitadores para a imposição das normas, do poder, das regras. Estão, notadamente, presos ao solo, às paredes, às demarcações estatais e privadas. Podem ser territórios visíveis, mas transpostos pelos vidros, janelas, fendas. Podem até ser pisados por aqueles que dele não fazem parte, mas esses estrangeiros sentirão a fadiga de estarem em local divergente. Não poderíamos, no entanto, classificarmos esses territórios como sendo 'apenas' visíveis, com fronteiras palpáveis, pois neles existe através das relações, a afetividade que, por sua vez, pode provocar afinidade, adesão, exclusão, amizade, paixão. Dessa maneira, os territórios se cruzam, se interpenetram.

Achamos por bem separar, ou tentar separar, os territórios palpáveis, visíveis, tocáveis daqueles construídos através dos encontros. 
São estes que pretendemos expor a partir de agora. Porém, esses territórios podem estar atrelados, de um jeito ou de outro, aos territórios concretos, delimitados por paredes e avisos, visíveis e palpáveis.

O caminho percorrido parece infinito até que o som do sinal da escola se mostre. Os movimentos solitários de um lado para o outro evita que outros corpos se aproximem. Sempre no mesmo trajeto os passos são concretizados sem parar. Parece uma marcha moderada de um atleta cansado. A lentidão do vai e vem deve estar relacionada à busca do som trazido pelo sinal. Na sala de aula, esse mesmo corpo, lá no fundo, busca limitar-se a olhar apenas para o seu limite físico imposto pelo acento da cadeira e apoio da mesa.

"Já tentamos conversar, mas ele não responde. Não que saber de fazer amigos. Ele não pratica esportes e na hora da educação física fica andando de um lado para o outro. É difícil aproximar-se dele". (Aluna do 90 ano do Ensino Fundamental)

Estaria o aluno caminhante se aventurando ao sair do seu território construído na sala de aula? Estaria ele sempre em processo de desterritorialização e reterritorialização, conforme apontou Deleuze (1988-1989)?

Enquanto os passos do caminhante não cessam, seis alunos, todos os dias, transformam um banco em mesa de truco. Como somente quatro pessoas podem jogar por partida, após o término da rodada, os dois que estavam fora do jogo iniciam outra "partida com os ganhadores". Sempre os seis juntos. Somente Homens. Às vezes outros param para olhar, mas dificilmente jogam. O deslocamento para jogar em outros lugares não é raro. Mas para isso o banco deve estar impedido por algum motivo.

"Esse banco é nosso. Até podemos sair daqui se algum funcionário da escola pedir. Mas quando ele estiver sem ninguém a preferência do banco é nossa". (Aluno do $1^{\circ}$ ano do Ensino Médio)

Próximo dali as duas, sempre as duas. Duas irmãs que não desgrudam. Pedido da mãe. Uma deve atender a outra. A de menor idade cuida da mais velha, pois pela inibição absurda da mais velha, a mais nova torna-se interlocutora oficial e autorizada pela mãe.

A cadeira colocada num pequeno local gramado entre o cimento da passagem e a delimitação física da escola. A grama, terreno sagrado; os passos não são permitidos; cadeiras muito menos. No entanto as duas e a cadeira colocada por elas é tão normal que ninguém solicita a retirada. Um local proibido que, por se tornar habitado pelas duas durante todo o tempo vago, nunca foi questionado. Um local que é legitimado como de alguém, mesmo sendo proibido pelas regras da escola.

"Nossa, até parece que uma não vive sem a outra; se uma fica doente e não vêm à escola a outra também não aparece. Coitadas, deve ser difícil viver assim". (Professora)

"Nunca vi coisa igual, ficam sempre no mesmo lugar. A gente passa 
por ali e nem percebe. Parece que fazem parte da grama". (Professora)

Legitimado também é o território que chamaremos de "caminhante". Um grupo de mais ou menos sete alunos que demarcaram como sendo deles um local próximo a entrada da secretaria. Sempre as mesmas pessoas. Todos adeptos do vídeo-game. Território "caminhante", pois esses alunos não permanecem o tempo todo nesse território, mas vão e vem. No entanto nenhum outro aluno se atreve, mesmo quando vazio, a "invadir" o local. O território físico não se desloca junto com os alunos quando eles caminham, mas o território subjetivo sempre está com eles. Mesmo quando há falta de alguém do grupo.

$\mathrm{Na}$ sala de aula a turma do "território caminhante" permanece unida num dos cantos do fundo da sala.

Próximo ao portão da escola, alguns meninos e meninas permanecem juntos. Mesmo fechado após o início das aulas, sempre que se buscasse alguém daquele grupo o território era o mesmo. Nessa turma os gostos musicais eram, no geral, muito parecidos. Inclusive o poder aquisitivo era destacado pelas vestes e pertences. Exceções à parte, os integrantes desse território estudavam na mesma sala de aula.

"Eles são muito unidos. Uns protegem os outros. Mesmo que o problema seja administrativo, relacionado à diretoria da escola". (Professor)

"Somos ligados mesmo fora da escola. Parece que somos sintonizados. Sempre mantemos contato por telefone,
Internet, e-mail". (Aluna do $1^{0}$ ano do Ensino Médio)

"Se mexer com um mexe com todos". (Aluno do $1^{\circ}$ ano do Ensino Médio)

Ao contrário do território do portão, o território existente atrás da quadra de esportes era formado por um grupo de três meninas. O Rap, único estilo musical permitido, podia ser ouvido através dos fones de ouvido.

"Nós gostamos de Rap, pois as músicas contam histórias que nós vivemos". (Aluna do $1^{0}$ ano do Ensino Médio)

Num outro território junto a um dos pilares de madeira que sustenta a cobertura de um pequeno corredor, as intelectuais sempre juntas não deixam os livros e cadernos nem nos momentos de descanso. Sempre juntas; alunas de salas diferentes têm como referência de encontro e ponto de estabelecimento, um pilar.

"Eu não aguento alguns alunos que falam de coisas sem sentido. Tem alunos na escola que nunca leram um livro em toda a vida. Como é que eu vou conversar com eles? Falar sobre o que? Além do mais são muito infantis." (Aluna do $3^{\circ}$ Ano do Ensino Médio)

Um latão de lixo no fundo de uma sala de aula de alunos do $2^{\circ}$ ano do Ensino Fundamental. Um território para conversas, risadas, recados, namoros, bilhetes. O acesso para o território devia ser aprovado pela professora que dava autorização ao aluno para apontar o lápis. 
Não demorava e outro aluno alegava que seu lápis também deveria ser apontado. Os recados numa folha de papel eram rapidamente passados sem que a professora pudesse perceber. Incrível tática demonstrada por alunos de sete e oito anos de idade. Os arredores de um recipiente de lixo no fundo de uma sala de aula como uma espécie de "território dos encontros". O latão de lixo como útil objeto de justificativa para o movimento dos corpos.

Por meio de um bilhete uma aluna convida um menino para um encontro no lixo:

"Se você gosta de mim, da próxima vez que eu voltar aqui para 'apontar' o lápis venha também para a gente se encontrar". (Bilhete de uma aluna de sete anos)

\section{Estratégias}

Tapas nas "cartinhas" ao chão. Um de cada vez. A intenção é virar o máximo de cartinhas possíveis. Aquelas viradas após os tabefes pertencem ao dono da mão que proferiu a agressão. Figuras de celebridades, super-heróis de desenhos animados estampam um dos lados do objeto estapeado. Um grupo de alunos amontoados e esperando a vez para jogar. As mãos vermelhas de tantos tapas desferidos, sem dó, nas cartas, são sempre assopradas logo após o golpe. Alguns esfregam as mãos para que fiquem suadas na tentativa de potencializar a ação.

Entusiasmados por simples cartinhas de papel. Territórios formados pela vontade de "bater cartinhas" com amigos da escola. Territórios formados pela afetividade entre grupos de amigos.

Certo dia, observando essa escola percebemos que muitos alunos que outrora estavam "batendo cartinha", agora não brincavam mais.

Aquilo nos intrigou e fomos, como curiosos e pesquisadores, obrigados a perguntar para um aluno viciado em bater cartinhas, o motivo pelo qual as cartinhas tinham sido deixadas de lado. Ele nos explicou:

"Isso é moda. Já estamos enjoados de bater cartinha. Hoje em dia todo mundo possui as cartinhas. Não tem mais o valor que tinham. Eu mesmo já dei as minhas para um amigo. Agora nós brincamos de jogar futebol e tênis de mesa."

Percebemos que a movimentação no pátio era bem maior. O pátio estava extremamente agitado. Diferente de dias anteriores. A correria e os gritos eram intensos.

Um fato nos chamou atenção naquele dia: uma fila enorme de meninos esperava para jogar tênis de mesa. Pela primeira vez naquele ano (2010) vimos os alunos jogando tênis de mesa na escola. Alguns apenas tocavam na raquete e já eram obrigados a voltar para o fim da fila. Outros com mais entrosamento com o esporte permaneciam por mais tempo.

Conversando com uma funcionária da escola descobrimos o motivo de a mesa ter sido armada no pátio.

"Agora que os alunos não querem mais saber das cartinhas tivemos que armar a tábua do tênis de mesa para que eles não fiquem correndo de um lado para 
o outro. Quando a moda acabar teremos de inventar outra coisa para que eles fiquem parados em algum lugar da escola. As cartinhas eram uma benção para nós." (Funcionária da escola)

Território do Tênis de mesa. Dos mais agitados. Dos meninos. Daqueles que brincavam de cartinha. Território construído para acomodar o incômodo. Estratégias do sistema para controlar

\section{Escola e metrópole: espaços correlacionados (?)}

No cotidiano escolar, na hora do intervalo os corpos têm seus limites estabelecidos. A cantina e o pátio, por exemplo, são separados.

A disciplina às vezes exige a cerca, a especificação de um local heterogêneo a todos os outros $e$ fechado em si mesmo. Local protegido da monotonia disciplinar. Houve o grande "encarceramento" dos vagabundos e dos miseráveis; houve outros mais discretos, mas insidiosos e eficientes. (FOUCAULT, 1987, p. 122 , grifo do autor)

Exemplo: insidiosos, discretos e eficientes. Merendeiras que buscam e entregam sem serem atrapalhadas e sem atrapalhar os sujeitos do pátio. As instalações das merendeiras não devem ser invadidas.

Diríamos que o progressivo crescimento diferenciado da malha urbana é acompanhado por um movimento concomitante de surgimento de novos segmentos sociais, gerados pelo processo político, econômico e cultural no interior das metrópoles. Deste modo, o famoso mito do anonimato das cidades é colocado em questão. Somos estranhos uns

\begin{abstract}
aos outros, mas buscamos constantemente resguardar um espaço dentro da urbe onde sejamos comuns e conhecidos, onde nossos signos encontrem reciprocidade. Somos habitantes desta confusa rede metropolitana, mas forjamos uma cartografia particular de seu traçado. Nossos roteiros e deslocamentos se inscrevem em um intrincado jogo de disputas, proibições e limites espaciais. Há os lugares de passagem. Há os de permanência, há também os horários convenientes e os espaços complementares proibidos ou vedados. (HAESBAERT, 2006, p. 94)
\end{abstract}

Haesbaert, falando de uma área metropolitana, mais precisamente o Rio de Janeiro, expõe a complexidade da urbe. É obvio que não queremos comparar o pátio e a cantina de uma escola com uma região metropolitana, mas sim exemplificar, por meio de uma metrópole, a complexidade que pode ocorrer num espaço escolar de maneira micro. E lembrar que as escolas são parte das metrópoles, das cidades, enfim carregam influências daquilo que vem de fora do cotidiano escolar. Disso poderia surgir a questão: o cotidiano escolar é como se fosse um espaço isolado do resto do mundo? Interessante questão, pois esses escritos podem levar a crer nisso. O mundo e o cotidiano escolar, separados. Entretanto, jamais poderíamos pensar em separá-los, mas poderíamos pensar no espaço escolar como um espaço carregado de características diferentes do espaço extra-escolar que, num momento ou outro, se encontram motivados por ações de seus sujeitos como, por exemplo, os trabalhadores, pesquisadores, artistas, etc. que passaram pela escola e depois retornam ao cotidiano escolar por meio dos trabalhos, dos filhos, das pesquisas. 
Esses microterritórios no/do/com o cotidiano escolar podem ser relacionados com uma metrópole até certo ponto; caso contrário, estaríamos passando dos limites no que tange ao comércio, à criminalidade, ao poder, à economia, ao trabalho etc. Na escola esses elementos não são descartados, mas a comparação seria desnecessária pela absurda diferença entre os espaços.

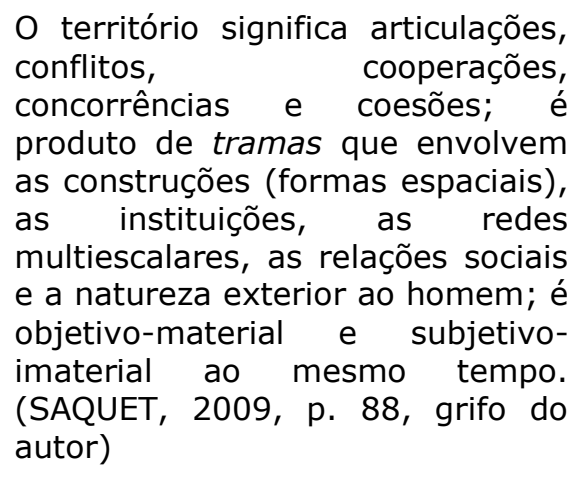

Quando fizemos a relação entre cotidiano escolar e metrópole, tivemos como intenção maior mostrar que nos dois espaços existem microterritórios e que esses microterritórios estão de certa forma, submetidos ao poder do Estado. No cotidiano escolar de escolas particulares brasileiras não é diferente; mesmo que indiretamente eles são capturados pelo poder do Estado por meio das diretrizes, normatizações e pela própria legislação que incumbe o Estado de fiscalizar as instituições de ensino particular.

Portanto, o cotidiano escolar e extra-escolar tem na

[r]egulação, a princípio entendida como uma instância de controle sobre o poder do mais forte e, portanto, voltada para a equalização de correlações de forças desiguais, acaba por se transmutar e passa a funcionar como mecanismo de controle sobre os mais fracos, a partir do momento em que suas formas reivindicatórias são entendidas como selvagens e, portanto, precisam ser coibidas pela instância reguladora. (OLIVEIRA, 2005, p. 27)

Após a pesquisa e a partir das muitas leituras realizadas foram ficando claras as infinitas possibilidades de se trabalhar com esse conceito. O território não está somente ligado ao solo e nem precisa estar ligado ao solo para ser considerado um território. Não necessita ser macro para se confirmar como território. As possibilidades de redefinição eram e são travadas, quase sempre, por concepções paradigmáticas.

A necessidade de ultrapassar a barreira do conceito de território é urgente; principalmente no espaço escolar onde emerge, talvez, a primeira reflexão sobre território por meio dos livros didáticos, do ensino de Geografia, dos professores e das próprias vivências cotidianas. Dessa forma, a pesquisa através do microterritório deve, não só transpor paradigmas, mas também possibilitar a aproximação do espaço escolar, assumido pelo Estado, onde trocas se metamorfoseiam dia após dia. 


\section{REFERÊNCIAS BIBLIOGRÁFICAS}

BOUTANG, Pierre-André; PARNET,Claire.. O Abecedário de Gilles Deleuze. Paris: Éditions Montparnasse/Brasil: TV Escola, Ministério da Educação.Tradução e Legendas: Raccord [com modificações], A transcrição integral do vídeo encontra-se disponível em: $<$ www.ufrgs.br/corpoarteclinica/obra/abc. prn.pdf > Último acesso em: 18.07.2011

FOUCAULT, Michel. Vigiar e punir: nascimento da prisão. Tradução de Raquel Ramalhete. Petrópolis, Vozes, 1987.

HAESBART, Rogério. Territórios Alternativos. 2a Edição. São Paulo: Contexto, 2006.

SAQUET, Marcos Aurélio; SPOSITO, Eliseu Savério. Territórios e territorialidades: teorias processos e conflitos (Orgs). $1^{\text {a }}$ Edição. São Paulo: Expressão Popular. UNESP. Programa de Pós-Graduação em Geografia, 2009. (Geografia em Movimento)
OLIVEIRA, Inês Barbosa de. Currículos praticados: entre a regulação e a emancipação. 2a Edição. Rio de Janeiro: DP\&A, 2005.

SOUZA, Marcelo José Lopes de. O território: sobre espaço e poder, autonomia e desenvolvimento. In: CASTRO, Iná Elias de; GOMES, Paulo Cesar da Costa; CORRÊA, Roberto Lobato. (Orgs). Geografia: Conceitos e Temas. 9a Edição. Rio de Janeiro: Bertrand Brasil, 2006, p. 77-116.

"Território" da divergência (e da confusão): em torno das imprecisas fronteiras de um conceito fundamental. In: SAQUET, Marcos Aurelio; SPOSITO, Eliseu Savério (orgs). Territórios e territorialidades: teorias, processos e conflitos. $1^{a}$ Edição. São Paulo: Expressão Popular. UNESP. Programa de Pós Graduação em Geografia, 2009, p. 57-72

\footnotetext{
* Professor efetivo de Geografia do Estado de São Paulo. Mestre em Educação ( 2011) pela Universidade de sorocaba - Uniso. Email: caromimar@yahoo.com.br

** Doutor pela Universidade Católica de Louvain. Pós-doutorado na Universidade de Genebra. Bolsista de Produtividade Científica do Cnpq (nível 2). Docente do PPG em Educacão da Universidade de Sorocaba - Uniso. Email: marcos.reigota@prof.uniso.br
} 